\title{
FERTILITY OF LACTATING JERSEY X HOLSTEIN-FRIESIAN COWS IN SUBTROPICAL REGION SUBMITTED TO A DOUBLE-OVSYNCH VERSUS OVSYNCH PROTOCOL FOR TIMED ARTIFICIAL INSEMINATION
}

\author{
A. A. Channa ${ }^{1}$, M. Aleem ${ }^{1}$, M. A. Jabbar ${ }^{2}$, H. Monir ${ }^{3}$ and N. Ahmad ${ }^{1 *}$ \\ ${ }^{1}$ Department of Theriogenology, Faculty of Veterinary Science, University of Veterinary and Animal Sciences, Lahore, \\ 54000, Pakistan; ${ }^{2}$ Department of Animal Nutrition, Faculty of Animal Production and Technology, University of \\ Veterinary and Animal Sciences, Lahore, 54000, Pakistan; ${ }^{3}$ Sapphire Dairy Farm, Kasur, Pakistan \\ "Corresponding author's E-mail address: nasimahmad@uvas.edu.pk
}

https://doi.org/10.36899/JAPS.2020.1.0030

Published online January 02, 2020

\begin{abstract}
Pre-synchronization prior to Ovsynch protocol is an efficient method to improve ovulation and pregnancy rate in dairy cows. The objective of this study was to define the effect of Double-Ovsynch (DOS; GnRH, PGF $_{2 \alpha} 7 \mathrm{~d}$ later and GnRH 2 $\mathrm{d}$ later followed by the OVS protocol with interval of $7 \mathrm{~d}$; timed AI 16 to $24 \mathrm{~h}$ after the last GnRH of OVS) and Ovsynch (OVS; GnRH, PGF $2 \alpha$ d later and GnRH $2 \mathrm{~d}$ later; timed AI 16- $24 \mathrm{~h}$ after the last GnRH) protocols on ovulation and pregnancy rate in crossbred dairy cows. The ovulation rate (day 7 post TAI, DOS $n=20$ vs. OVS $n=21$ ) and pregnancy rate (day 35 post TAI, DOS $n=125$ vs. OVS $n=148$ ) were determined using ultrasonography. Serum concentrations of progesterone on $\mathrm{d} 7$ after the last GnRH of each protocol was determined in the subset of randomly selected cows (DOS $n=10)$ and (OVS $n=10)$ protocol. The Ovulation rate $(\mathrm{OR})$ was higher $(\mathrm{P}<0.05)$ in DOS as compared to OVS $(90 \%$ vs. $47 \%)$ protocols. Likewise, pregnancies per AI (P/AI) significantly $(\mathrm{P}<0.05)$ increased in DOS as compared to OVS $(62$ $\%$ vs. $30 \%)$. Mean serum concentrations of progesterone on d 7 remained similar $(\mathrm{P}>0.05)$ between DOS and OVS $(8.68 \pm 0.78 \mathrm{ng} / \mathrm{mL}: 8.19 \pm 1.85 \mathrm{ng} / \mathrm{mL})$ protocols. It is concluded that DOS compared to OVS yields better ovulation and pregnancy rate in crossbred dairy cows.
\end{abstract}

Key words: Ovsynch; Double-Ovsynch; Ovulation; Pregnancy; Crossbred cows

\section{INTRODUCTION}

Commercial dairy farming with exotic herds comprising of Holstein, Jersey and their crosses, is one of the fast growing industries in tropical and sub-tropical countries. Reproduction, in high milk yielding dairy cows, is the key to profitability. However, estrus detection and estrus expression rate are less and lead to overall lowered fertility and increased calving interval (Washburn et al. 2002,Lopez-Gatius et al. 2005,Wiltbank et al. 2006). To overcome heat detection in large dairies, estrus and ovulation synchronization protocol (Ovsynch) was developed (Pursley et al. 1995) in United State of America (USA) which had a provision to breed cows at fixed time. The Ovsynch is a hormonal regime in which gonadotropin-releasing hormone $(\mathrm{GnRH})$ and Prostaglandin $\mathrm{F}_{2 \alpha}(\mathrm{PG})$ are used. GnRH induces ovulation and PG causes luteolysis of the corpus luteum (CL). The fertility though was lower in TAI with that of detected estrus using synch (Tenhagen et al. 2004). The plausible reason for lowered fertility is the variation in the ovulatory response due to the stage of cycle (Vasconcelos et al. 1999).

The presence of large follicle at the time of $1^{\text {st }}$ GnRH of Ovsynch protocol improves the ovulation and pregnancy rates in dairy cattle (Vasconcelos et al. 1999).
Therefore, prior to the Ovsynch, some presynchronization regimes were developed in order to enhance the success of this protocol. This included use of single PG (LeBlanc and Leslie 2003), double PG (Moreira et al. 2001) , G6G (Bello et al. 2006) and Double-Ovsynch (Souza et al. 2008). The results from the pre synchronization with PG indicated its ineffectiveness to induce cyclicity in an-ovular cows (Moreira et al. 2001) whereas Double-Ovsynch protocol was able to induce cyclicity in acyclic lactating Holstein cows and enhanced ovulation and pregnancy rate of ensuing Ovsynch protocol (Astiz and Fargas 2013). The information regarding the success of the double Ovsynch protocol in crossbred cows in sub-tropical large dairy herds is lacking. Therefore, the present experiment was designed to compare Ovsynch and Double-Ovsynch protocol for ovulation and pregnancy rate in crossbred cows.

\section{MATERIALS AND METHODS}

Animals and management: Lactating crossbred (Friesian $\mathrm{x}$ Jersey $\mathrm{n}=273$ ) dairy cows from a commercial dairy farm located in District Kasur of Punjab province of Pakistan were used in the present experiment, conducted from November 2015 to February 2016. These 
experimental cows were accommodated in free stall barns, and fed with total mixed ration formulated at farm with $24 \mathrm{~h}$ free access to fresh water. These crossbred dairy cows were randomly selected to receive two different breeding groups or protocols; 1. DoubleOvsynch (DOS n=125)2. Ovsynch (OVS n=148). From each group, a subset of cows was randomly assigned, DOS $n=20$ and OVS $n=21$ for determination of ovulation. Furthermore, within each subset of cows, ten cows were randomly selected for blood sampling for determination of progesterone concentrations. These cows were at 60180 days post-partum having body weight $480 \pm 18 \mathrm{Kg}$ with BCS $3.5 \pm 0.35$ ( 1 as thin and 5 obese as described by Ferguson et al.1994). These animals were ensured through rectal palpation that they had no abnormalities in their reproductive tracts.

Hormonal treatments, AI and blood collection: Crossbred cows $(n=273)$ were randomly divided into two treatments without determining the stage of estrous cycle (1) DOS; Double-Ovsynch (GnRH, $7 \mathrm{~d} \mathrm{PGF}_{2 \alpha}, 2 \mathrm{~d}$ GnRH, 7 d later GnRH, 7 d PGF $2 \alpha, 2$ d GnRH, 16 24 hour-TAI $\mathrm{n}=125)$ and (2) OVS; Ovsynch (GnRH $7 \mathrm{~d} \mathrm{PGF}_{2 \alpha} 2 \mathrm{~d}$ GnRH 16 24 hour-TAI $n=148$ ). Inseminations in all cows were performed with commercially available imported Holstein-Friesian bull frozen thawed semen (25 x $10^{6}$ sperm / dose) by single technician. Ovulations were determined in a subset of cows (OVS $n=21$ and DOS $n=$ 20) seven days post TAI and pregnancy diagnosis was carried out at day 35 post TAI in all the cows enrolled in the both groups/protocols. The time line of the experiment is presented in (Fig. 1). The hormones used for synchronization programs were $\mathrm{PGF}_{2 \alpha}$ (Dalmazin, 2 $\mathrm{mL}$ i.m.,Cloprostenol sodium $0.075 \mathrm{mg} / \mathrm{mL}$; Fatro, Italy) and GnRH (Dalmarelin $4 \mathrm{~mL}$ i.m., Lecirelin acetate 25 $\mu \mathrm{g} / \mathrm{mL}$; Fatro, Italy). Seven days after TAI, ovulations were confirmed by visualization of CL, and pregnancy was diagnosed using trans-rectal linear transducer (Honda HS1500 Tokyo, Japan). Furthermore, for determination of P4 concentrations at day 7 after TAI, blood samples from ten randomly selected cows from each subset were withdrawn through tail vein puncture and placed in a vacutainer without anticoagulant (BD Vacutainer, by Preanalytical Solutions, Franklin Lakes, NJ).

Progesterone Estimation: The blood samples which were collected on day 7 after last GnRH injection of each protocol to determine the serum progesterone (P4) concentrations from each cow. Serum was separated after centrifugation (3000 rpm) from blood sample and stored at $-20{ }^{\circ} \mathrm{C}$ until assay. $\mathrm{P} 4$ assay was performed through commercially available competitive kit (DSI, P4 ELISA, Diagnostic Systems Ltd, Italy). The minimum detection level $0.156 \mathrm{ng} / \mathrm{mL}$ while coefficient of variation in intraassay and was 3.5 and $6.2 \%$ respectively.
Statistical Analysis: Ovulation and pregnancy per AI was analyzed using binary logistic regression test using Statistical Analytical System for Windows (SAS 9.2 Institute Inc, Cary, NC, USA). Student's t-test was used to determine the difference between DOS and OVS protocol for progesterone levels using Statistical Software SPSS (version, 20, 2017).

\section{RESULTS AND DISCUSSION}

Effect of synchronization protocol on ovulation rate, serum concentrations of $\mathrm{P} 4$ and pregnancy/A.I in crossbred cows of this study are presented in Fig. 2. The outcomes of the present study revealed that ovulation rate was significantly high in DOS than OVS (90\% vs. $47 \%$; $\mathrm{P}<0.05$, respectively). The pregnancy rate was also higher $(62 \%$ vs. $30 \%, \mathrm{P}<0.05)$ in DOS than OVS. Serum progesterone concentrations after 7-days from last $\mathrm{GnRH}$ in each protocol was similar i.e., DOS; $8.68 \pm 0.78$ and OVS $8.19 \pm 1.85 \mathrm{ng} / \mathrm{mL}(\mathrm{P}>0.05)$. The suitability and successful induction of the DOS in various synchronization regimens has previously been reported in Holstein cows to improve the ovulation rate and fertility (Souza et al. 2008, Herlihy et al. 2012, Santos et al. 2017). Similarly, the findings of our study support the hypothesis that by using DOS protocol pregnancy rate in crossbred dairy cows can be enhanced under subtropical conditions. The results of this study revealed that the pregnancy rate in crossbred multiparous lactating cows was improved by $32 \%$ in DOS as compared to OVS. Similar findings have been reported in primiparous lactating Holstein cows where DOS protocol ensued 20\% more pregnancy rate as compared to control groups (Souza et al. 2008).In contrast to our findings, DOS protocol did not improve the pregnancy rate in multiparous lactating Friesian cows (Souza et al. 2008). The recent meta-analysis conducted by (Borchardt et al. 2017), reported over all improved pregnancy rate in cows went under Double-Ovsynch protocol in general and lower specifically in multiparous cows. The variation in results of these experiments might be ascribed by the number of calvings, lactation yield, general management and dose of hormone for commencement of DOS protocol (Souza et al. 2008).

In the present study, the application of DOS protocol demonstrated better ovulation rate than OVS (90 $\%$ vs. $47 \%$ ). These outcomes are in agreement with earlier report in Holstein dairy cows in which the DOS enhanced the ovulation rate and fertility (Ayres et al. 2013). It is well documented that DOS increase fertility in cows by two mechanisms firstly by causing ovulation in acyclic cows, in response to the first part of DOS protocol so the response to subsequent hormonal injection becomes better and secondly by increasing the progesterone at the time when the second part of DOS is initiated (Souza et al. 2008). 
The present study demonstrated that, DOS increased ovulation and pregnancy (P/A.I) in crossbred cows. These finds are in close agreement with previous studies which reported higher ovulation and pregnancy rate in DOS protocol followed by fixed time AI in lactating Holstein dairy cows as compare to the Ovsynch protocol (Souza et al., 2008; Ayres et al., 2013; Giardano et al., 2013). The increased pregnancy rate using DOS is already reported in anestrous Holstein dairy cows and primiparous cows compared to standard OVS (Souza et al. 2008, Öztürk et al. 2010,). The DOS protocol yielded higher ovulation, synchronization rate and greater pregnancy P/A.I as compared to other pre-synch protocols even in heat stress lactating dairy cows (Dirandeh et al. 2015).. The enhanced fertility with Double-Ovsynch may be related to high progesterone during the follicular phase, that reduce the LH (Lutenizing Hormone) secretion and improve the quality of dominant follicle or oocyte (Mihm et al. 1994, Ferreira and Wiltbank 2008, Souza, Ayres et al.2013).The results of the present experiment for post AI progesterone at day seven did not differ in the two protocols. For supporting the pregnancy, progesterone concentrations could be one of the factors for the successful pregnancy (Mann and Lamming 1999).

\section{Oysynch $(n=148)$}

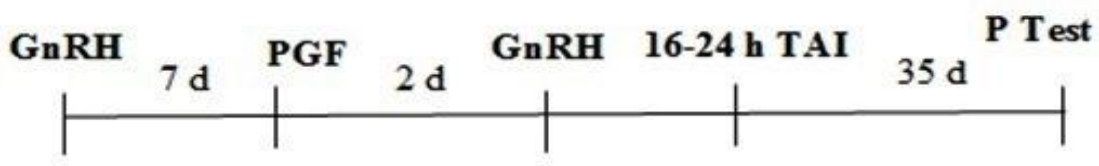

Double-synch $(\mathrm{n}=125)$

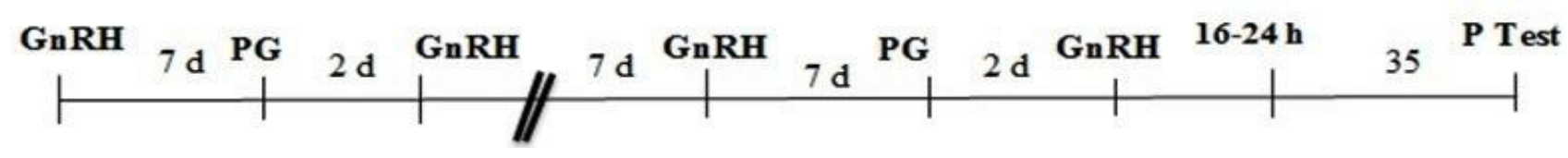

Fig. 1. Schematic diagram of synchronization protocols; Double-Ovsynch and Ovsynch in crossbred dairy cows

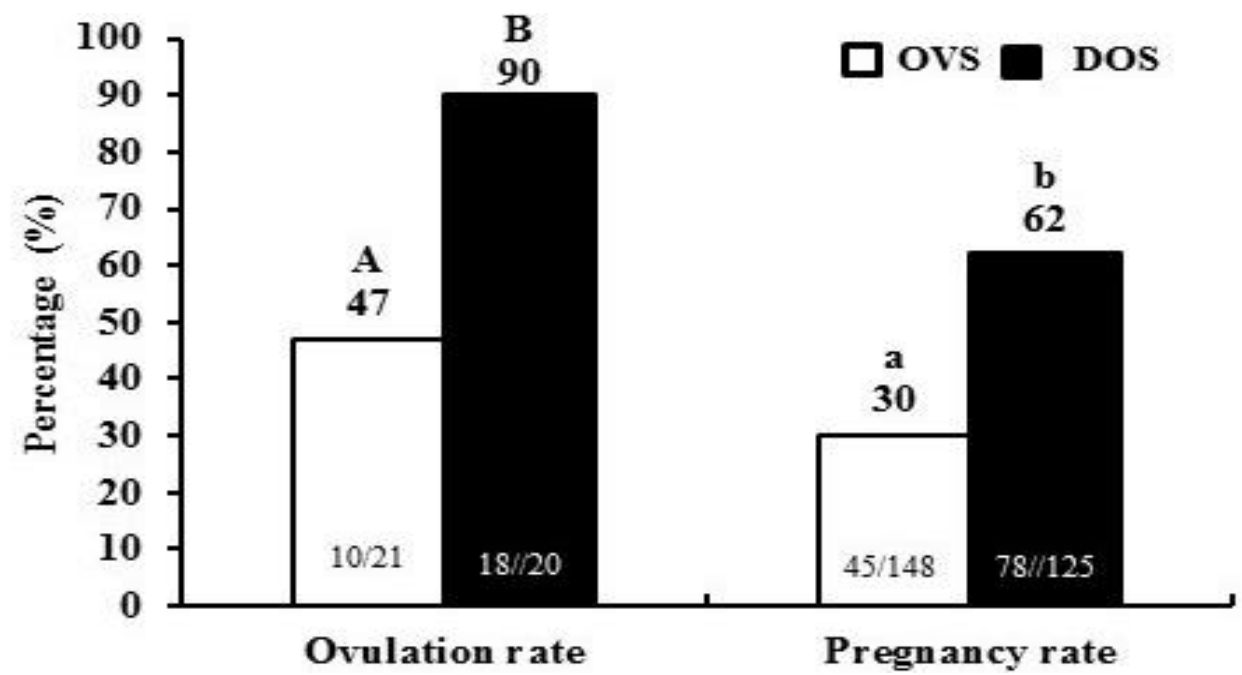

Fig. 2. Effect of synchronization protocols (DOS, double Ovsynchvs OVS, Ovsynch)on ovulation rate and

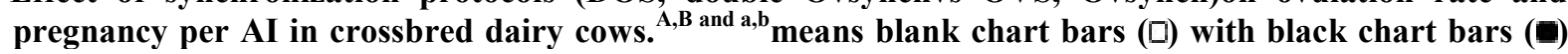
different superscripts differ $(P<0.05)$. The numbers in boxes indicate the number of cows.

Conclusion: Taken together, it can be concluded that these data are new and solid that DOS resulted in higher ovulation and pregnancy rate than OVS in crossbred dairy cows. The most likely the driver for this higher fertility is the enhanced ovulation rate. It is implied that DOS as a pre-synchronization tool can be used safely in tropical and sub-tropical areas particularly when the herd fertility is compromised (This paper is based on a part from $\mathrm{PhD}$ research thesis)

Statement of Novelty: The Ovsynch is a normal routine reproductive management protocol with variable pregnancy rates at different farms and locations. In the present experiment, Ovsynch and Double-Ovsynch have 
been compared for ovulation and pregnancy rate followed by fixed timed AI in crossbred dairy cows.

\section{REFERENCES}

Astiz S.,and O. Fargas (2013). Pregnancy per AI differences between primiparous and multiparous high-yield dairy cows after using Double Ovsynch or G6G synchronization protocols. Theriogenology, 79: 1065-1070.

Ayres H., R. M. Ferreira, A. P. Cunha, R. R. Araujo and M. C. Wiltbank (2013). Double-Ovsynch in high-producing dairy cows: effects on progesterone concentrations and ovulation to GnRH treatments. Theriogenology, 79: 159-164.

Bello N. M., J. P. Steibel and J. R. Pursley (2006). Optimizing ovulation to first GnRH improved outcomes to each hormonal injection of ovsynch in lactating dairy cows. J Dairy Sci, 89: 3413 3424.

Borchardt, S., P. Haimerl, A. Pohl and W. Heuwieser (2017). Evaluation of prostaglandin $\mathrm{F}_{2 \alpha}$ versus prostaglandin $\mathrm{F}_{2 \alpha}$ plus gonadotropin -releasing hormone as Presynch methods preceding an Synch in lactating dairy cows : A meta-analysis. J. Dairy Sci., 100:4065-4077

Chebel R. C., J. E. Santos, J. P. Reynolds, R. L. Cerri, S. O. Juchem, and M. Overton (2004). Factors affecting conception rate after artificial insemination and pregnancy loss in lactating dairy cows. Anim Reprod Sci, 84: 239-255.

Dirandeh E., A. R. Roodbari and M. Colazo (2015). Double-Ovsynch, compared with presynch with or without GnRH, improves fertility in heatstressed lactating dairy cows. Theriogenology, 83: 438-443.

Ferguson J. D., D. T Galligan and N. Thomsen (1994). Principal descriptors of body condition score in Holstein cows. J. Dairy Science 77(9): 2695 2703.

Giordano J. O., M. C. Wiltbank, P. M. Fricke, S. Bas, R. Pawlisch, J. N. Guenther and A. B. Nascimento (2013). Effect of increasing GnRH and PGF2alpha dose during Double-Ovsynch on ovulatory response, luteal regression, and fertility of lactating dairy cows. Theriogenology, 80: 773-783.

Herlihy M. M., J. O. Giordano, A. H. Souza, H. Ayres, R.M. Ferreira, A. Keskin, A. Nascimento, J. N. Guenther, J. M. Gaska, S. J. Kacuba, M. A. Crowe, S. T. Butler and M. C. Wiltbank ( 2012). Presynchronization with Double-Ovsynch improves fertility at first postpartum artificial insemination in lactating dairy cows. J Dairy Sci, 95: 7003-7014.

LeBlanc S. and K. Leslie (2003). Presynchronization using a single injection of PGF2 $\alpha$ before synchronized ovulation and first timed artificial 
insemination in dairy cows. J Dairy Sci, 86 : 3215-3217.

Lopez-Gatius F., M. Lopez-Bejar, M. Fenech and R. H. Hunter (2005). Ovulation failure and double ovulation in dairy cattle: risk factors and effects. Theriogenology, 63: 1298-1307.

Mann G. and G. Lamming, (1999). The influence of progesterone during early pregnancy in cattle. Reprod Domest Anim, 34: 269-274.

Mihm M.,N. Curran,P. Hyttel, M. Boland and J. Roche (1994). Resumption of meiosis in cattle oocytes from preovulatory follicles with a short and a long duration of dominance. J Reprod Fertil, 13: 14.

Moreira F.,C. Orlandi,C.A. Risco,R. Mattos,F. Lopes, and W.W. Thatcher(2001). Effects of presynchronization and bovine somatotropin on pregnancy rates to a timed artificial insemination protocol in lactating dairy cows. J Dairy Sci, 84 : 1646-1659.

Pursley J. R., M. O. Mee, and M. C. Wiltbank (1995). Synchronization of ovulation in dairy cows using PGF2alpha and GnRH. Theriogenology, 44: 915-923.

Santos V.G., P. D. Carvalho, C. Maia, B. Carneiro, A. Valenza and P. M. Fricka (2017). Fertility of lactating Holstein cows submitted to a Double Ovsynch protocol and timed artificial insemination versus artificial insemination after synchronization of estrus a similar day in milk range. J Dairy Sci.100:8507-8517

Souza A. H., H. Ayres, R. M. Ferreira, and M. C. Wiltbank (2008). A new presynchronization system (Double-Ovsynch) increases fertility at first postpartum timed AI in lactating dairy cows. Theriogenology, 70: 208-215.

Tenhagen B.A., M. Drillich, R. Surholt, and W. Heuwieser (2004). Comparison of timed AI after synchronized ovulation to AI at estrus: Reproductive and economic considerations. J. Dairy Sci, 87: 85-94.

Vasconcelos J. L, R. W. Silcox, G. J. Rosa, J. R. Pursley and M.C. Wiltbank(1999). Synchronization rate, size of the ovulatory follicle, and pregnancy rate after synchronization of ovulation beginning on different days of the estrous cycle in lactating dairy cows. Theriogenology, 52: 1067-1078.

Washburn S.,W. Silvia, C. Brown,B. McDaniel, and A. McAllister (2002). Trends in reproductive performance in southeastern Holstein and Jersey DHI herds. J Dairy Sci, 85: 244-251.

Wiltbank M., H. Lopez,R. Sartori,S. Sangsritavong, and A. Gümen (2006). Changes in reproductive physiology of lactating dairy cows due to elevated steroid metabolism. Theriogenology, 65: 17-29. 